\title{
Radiation Therapy Oncology Group
}

National Cancer Institute

\section{Source}

National Cancer Institute. Radiation Therapy Oncology Group. NCI Thesaurus. Code C19778.

A multi-institutional cooperative organization, a national cancer study research group comprised of 250 of the major research institutions nationally and in Canada, funded by $\mathrm{NCl}$, headquartered in Philadelphia with almost 30 years of experience in running clinical trials. More than 40 clinical trials that involve radiation therapy either alone or in conjunction with surgery and/or chemotherapeutic drugs are active at any one time within RT OG. The group is interested in quality of life issues and their effects on the cancer patient 